\title{
Investigation of a ship's hydroelasticity and seakeeping performance by means of large-scale segmented self-propelling model sea trials"
}

\author{
Jia-long JIAO ${ }^{1}$, Hui-long REN ${ }^{\dagger 1}$, Shu-zheng SUN ${ }^{1}$, Christiaan Adika ADENYA ${ }^{1,2}$ \\ ( ${ }^{1}$ College of Shipbuilding Engineering, Harbin Engineering University, Harbin 150001, China) \\ ( ${ }^{2}$ Department of Marine Engineering and Maritime Operations, Jomo Kenyatta University of Agriculture and Technology, Nairobi, Kenya) \\ †E-mail: renhuilong@hrbeu.edu.cn
}

Received Aug. 1, 2015; Revision accepted Dec. 15, 2015; Crosschecked May 11, 2016

\begin{abstract}
The traditional laboratory models for the hydroelasticity and seakeeping performance of ships are tested in calm water and in uni-directional, artificially generated waves. A new alternative to the tank model measurement methodology is to conduct experiments using large-scale models in actual sea conditions. To implement the tests, a large-scale segmented self-propelling model and testing system were designed and assembled. A buoy wave meter was adopted to record the coastal waves that the model encountered during the tests. The analysis of the results of waves in sheltered waters by the spectral method shows good agreement with ISSC spectra. To investigate the difference between this new methodology and the traditional towing tank tests, a small-scale model, whose type and configuration are the same as those of the large-scale model ship, was used and tests were conducted in a towing tank. Comparison of the two experimental results shows that there is a remarkable difference in the response characteristics between the large-scale model at sea and the small-scale model in the tank. Numerical simulations of the responses of the ship under equivalent sea states were also carried out. The influence of directional spreading functions on the results was analyzed by a numerical approach. The classical model tests under long-crested waves in the towing tank over-estimate the motion and wave load responses; however, large-scale model tests carried out at sea are more reasonable for ship design and scientific research.
\end{abstract}

Key words: Hydroelasticity, Seakeeping performance, Segmented model test, Large-scale model test, Sea trial, Scale effects http://dx.doi.org/10.1631/jzus.A1500218 CLC number: U661.73

\section{Introduction}

Since hydroelasticity and seakeeping performance issues involve the interactions of an arbitrary shaped moving body with a fluid, which is quite complicated and cannot be dealt with well by numerical methodologies, experiments constitute an invaluable tool in the field of naval architecture.

\footnotetext{
${ }^{\ddagger}$ Corresponding author

* Project supported by the National Natural Science Foundation of China (Nos. 51079034 and 51209054), and the Basic Research Foundation of Harbin Engineering University (No. HEUCFR1201), China (DD ORCID: Jia-long JIAO, http://orcid.org/0000-0001-5740-8865

(C) Zhejiang University and Springer-Verlag Berlin Heidelberg 2016
}

However, most hydrodynamic experiments of naval architecture and ship engineering are performed in hydrodynamic basins using small-scale models (Grigoropoulos and Katsaounis, 2004). Usually the small-scale ship models are carried out in calm water or in artificially generated long-crested waves. In addition, usually the motion signals of small-scale models are measured by seaworthiness instruments, which will restrict the freedom of motion of the models in some way. A few state-of-the-art tank facilities which can generate multidirectional, pseudorandom waves were built by some large research institutions. Although these towing tanks have the lengths of several hundred meters, the limitations of 
model size and towing speed also restrict measurement. The full-scale ship test is the most authentic and reliable method, but the costs and time needed for real ship sea trials are tremendous. In addition, extremely severe sea states would pose a major threat for the crews and ships (Shi, 2007; Zhao, 2008; Wang, 2009).

To overcome the limitations of current testing methods, large-scale ship models are proposed to conduct experimental tests in coastal seas. The models are usually of radio-controlled design, and many kinds of hydrodynamic experiments can be performed using this method, e.g., calm water resistance, propulsion, underwater explosion, seakeeping performance, wave load, and manoeuvring tests. There are many other advantages of this testing method, such as the elimination of the need to construct expensive towing facilities and the reduction of scale effects by using large models. The waves which the model encounters are 3D non-linear sea waves since it is conducted under natural sea states. In this condition the motion and wave load responses of the model are of full non-linear effects. This is of great significance for the experimental research of 3D non-linear hydroelasticity and seakeeping performance theories.

Currently, in some countries-for example, Britain, France, the United States, Greece, and Italytesting technologies of large-scale models have been highly developed. Different testing methods for large-scale models in real sea states are performed. However, owing to the great superiority of this technique, published papers are, for the sake of secrecy, limited to model introductions or experimental data. Several researchers have studied the design and seakeeping performance of large-scale model tests (Sun et al., 2009). Large-scale model experiments have also been conducted on the propeller behavior of a free running model in a lake (Coraddu et al., 2013). However, there have been no papers published relating to hydroelastic tests of large-scale models at sea, according to the authors' knowledge. Since hydroelasticity is important for evaluating the behavior of large ships with increasing tonnage in extreme sea states, this paper mainly focuses on the investigation of the hydroelasticity and seakeeping performance of large-scale model tests.

First, for the hydroelastic and seakeeping performance tests in actual sea states, a self-propelled large-scale ship model is adopted. The designs of the ship model and the testing system are introduced in detail in this paper. Second, experimental procedures and results are described, including the wave measurement and the model's response results. Then traditional tests using small-scale models are carried out in a towing tank, and the results from the large-scale and small-scale model tests are compared. Finally, in-house-developed wave load software is used to calculate the responses of the ship under equivalent sea states for the comparative study of large-scale model tests.

\section{Experimental design for large-scale model tests}

\subsection{Model design}

A fiberglass reinforced plastic (FRP) large-scale segmented model was built to investigate the wave load characteristics and seakeeping performance of a large ship. There is a steel backbone system fixed at the vertical bending neutral axis of the model. The scale ratio of the large-scale model is chosen as 1:25 as a compromise between the model manufacture and testing requirements. The main dimensions of the models are shown in Table 1. In this table, VCG is vertical center of gravity, BL is baseline, LCG is longitudinal center of gravity, AP is after perpendicular, $K_{x x}$ is transverse radius of gyration, and $K_{y y}$ is longitudinal radius of gyration.

The model has 20 stations and it was cut into seven parts of segmented hulls at the cross-sections of the 2nd, 4th, 6th, 8th, 10th, and 12th stations. Wave-induced vertical bending loads at these cut sections are measured by strain gauges, which are glued onto the surface of the backbone, using a full-bridge circuit. Sections 13 to 20 at the stern cannot be cut, due to the need for installing motors and shafts (Jiao et al., 2015). Arrangements of the model and the measuring equipment installed on the model are schematized in Fig. 1.

Hollow tubular structure steel backbones are designed and assembled on this ship model. Backbones of hollow tubular form not only lighten the backbones' weight, but could also simulate torsional or horizontal bending modes in addition to the vertical bending mode at the same time. The sectional 
dimensions of the backbone are determined to simultaneously match the natural frequencies of vertical bending and torsional modes of the vessel (Chen et al., 2012). The backbone is made with different crosssectional parameters for width and height at different sections. Changes to the sectional dimensions are made at the cut sections. Rectangular steel backbones are adopted from the 1 st to 5 th sections and the 7 th to 13 th sections to measure sectional hull girder vertical bending moment (VBM). A cylindrical steel backbone is adopted from the 5th to 7th sections to measure sectional hull girder VBM and torsional moment (TM). Fixing systems are installed at the 1st, 3rd, 5th, 7th, 9th, 11th, and 13th sections to fix the backbone to the segmented hulls rigidly. The model's backbones are shown in Fig. 2a. The connections of the rectangular backbone with the cylindrical backbone as well as the fixing systems are shown in Fig. $2 b$.

Table 1 Main dimensions of the models

\begin{tabular}{lcc}
\hline \multicolumn{1}{c}{ Principal dimension } & $\begin{array}{c}\text { Large-scale } \\
\text { model }\end{array}$ & $\begin{array}{c}\text { Small-scale } \\
\text { model }\end{array}$ \\
\hline Scale ratio & $1: 25$ & $1: 50$ \\
Overall length (m) & 12.52 & 6.26 \\
Waterline length (m) & 11.68 & 5.84 \\
Moulded breadth (m) & 1.58 & 0.79 \\
Depth (m) & 1.02 & 0.51 \\
Draft (m) & 0.40 & 0.20 \\
Displacement (kg) & 4600 & 575 \\
VCG from BL (m) & 0.64 & 0.32 \\
LCG from AP (m) & 5.62 & 2.81 \\
$K_{x x}(\mathrm{~m})$ & 0.54 & 0.27 \\
$K_{y y}(\mathrm{~m})$ & 2.92 & 1.46 \\
\hline
\end{tabular}

The propulsion of the model is achieved by using four five-blade AU-type screw propellers. The four propellers are driven by two DC $120 \mathrm{~V}$ brushless electric motors. The rated power of each motor is $5 \mathrm{~kW}$. Since air is needed when an internal combustion engine is used to propel the model, this option is disadvantageous because the model hull has to be airproof. Thus, electric motors have been selected over internal combustion engines. In addition, electric

(a)

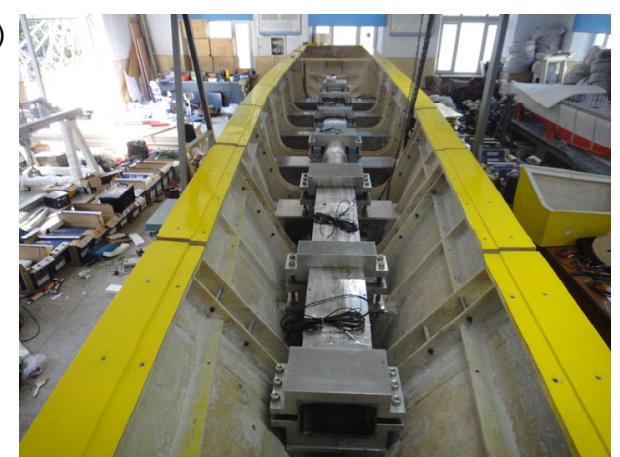

(b)

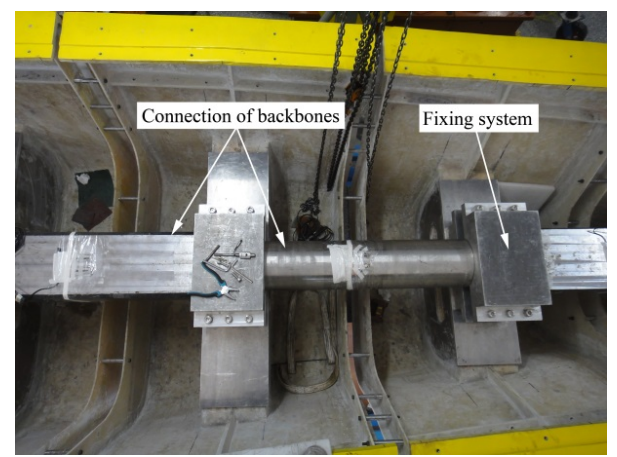

Fig. 2 Backbone system

(a) Overview of backbone model; (b) Connection of rectangular and cylindrical backbones

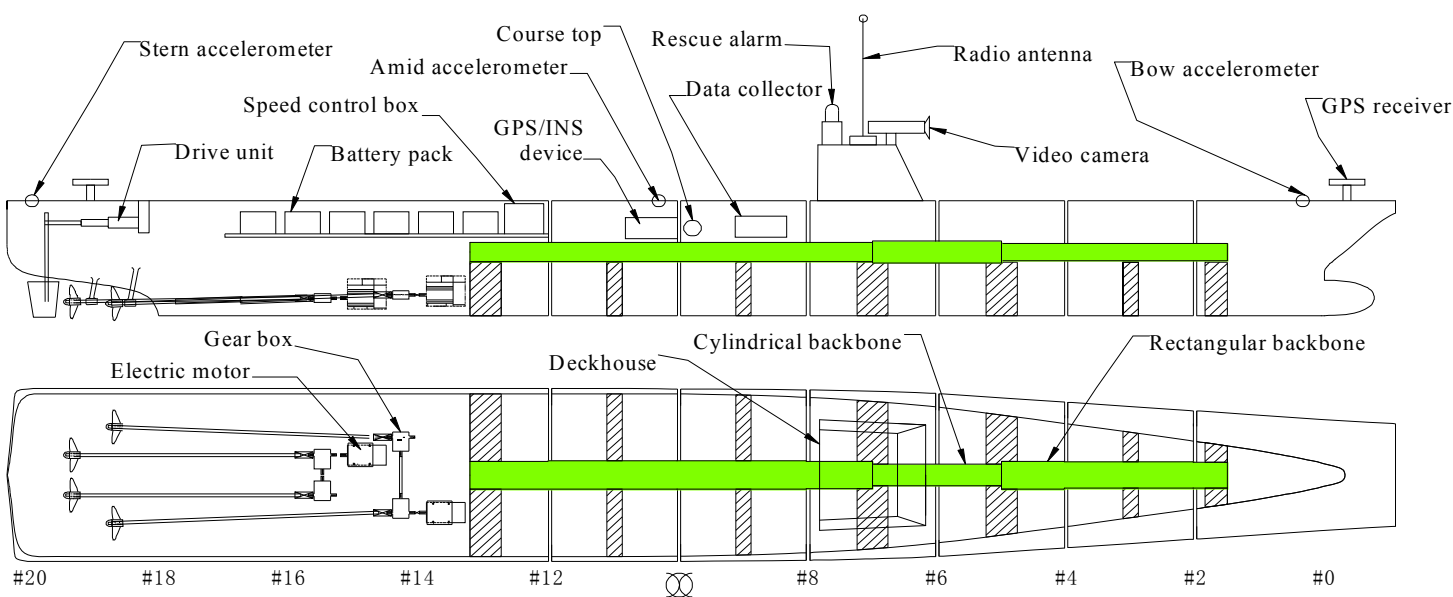

Fig. 1 Arrangement of model setup 
motors provide excellent controllability during the experiment. The cross-connection gear boxes are important components of this plant, because they drive two shafts using one electric motor. The connection method of the propulsion system can be seen in Fig. 1. To propel the model and activate all the electric facilities onboard, 14 blocks of storage batteries, of DC $12 \mathrm{~V}$, are used. On the other hand, the batteries also act as ballast load. The speed of the motor is regulated by the control system onboard the model. Twin rudders of the model are controlled by an autopilot system to keep on course. The arrangement of screw propellers and rudders at the stern area of the model can be seen in Fig. 3.

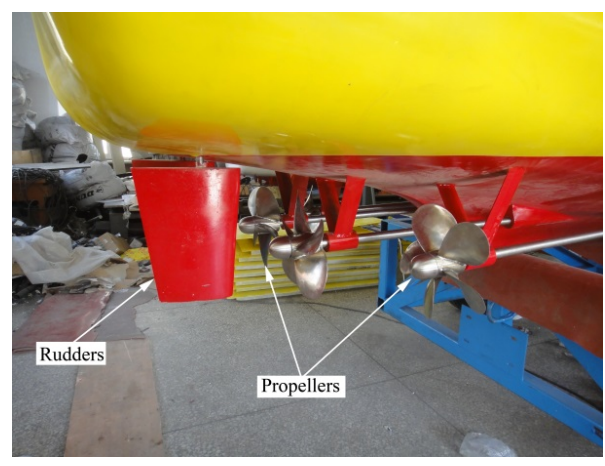

Fig. 3 Arrangement of screw propellers and rudders

\subsection{Testing system}

The testing system is of great importance during the tests, in particular at high speeds or in severe seas, because large-scale model hulls experience enormous loads and it is easy to lose control. An auxiliary workboat and wave measurement boat are also used to carry out the tests.

The unmanned large-scale model is fully equipped with technical devices during the measurement. The testing system can be classified into four central sub-systems: a Global Position System/ Inertial Navigation System (GPS/INS) device, a model control system, a data acquisition system, and a safety guard system. These sub-systems are described as follows.

\subsubsection{GPS/INS device}

A commercial GPS/INS device is adopted for the measurement of the model sailing track, speed, course, and motion information. The device has a measuring accuracy of course angle within $0.05^{\circ}$, pitch and roll angles within $0.02^{\circ}$, and speed within $0.02 \mathrm{~m} / \mathrm{s}$. The core apparatus of INS is fixed at the center of gravity of the model. The communications between the test model and auxiliary workboat are achieved by radio. The sampling frequency of the GPS/INS device is set at $10 \mathrm{~Hz}$ during the tests. Fig. 4 shows the software interface of the GPS/INS device, where the model's navigation information is presented. The radio works at a frequency range of $220-235 \mathrm{MHz}$ in an effective radius of $10 \mathrm{~km}$. The maximum radio communication rate is $65000 \mathrm{bits} / \mathrm{s}$ and the maximum cable radio communication rate is $115200 \mathrm{bits} / \mathrm{s}$.

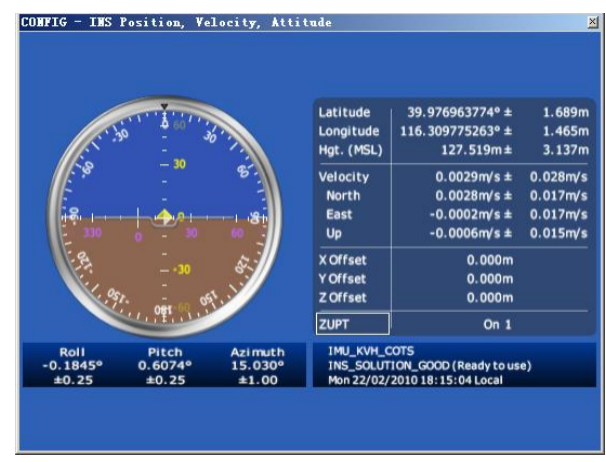

Fig. 4 Interface of the GPS/INS software

\subsubsection{Model control system}

To control the model's heading angle and sailing speed during measurements, a control system has been designed and assembled. The flowchart of the remote control system is presented in Fig. 5. The model sailing state, e.g., speed components and heading angle, is displayed on the interface of the GPS/INS software (Fig. 4). Input commands are achieved by the remote control system so as to change the model's sailing speed or course, or both.

The model is designed with the capacity of a $3.086 \mathrm{~m} / \mathrm{s}$ sailing speed even in severe seas, which corresponds to a ship prototype speed of 30 knots. The engine speed is regulated by the input exciting voltage (Sun et al., 2010). The motor speed is proportional to the input exciting voltage. The exciting voltage ranges from 0 to $5000 \mathrm{mV}$. An exciting voltage of $5000 \mathrm{mV}$ corresponds to the maximum speed capacity of the motors. 


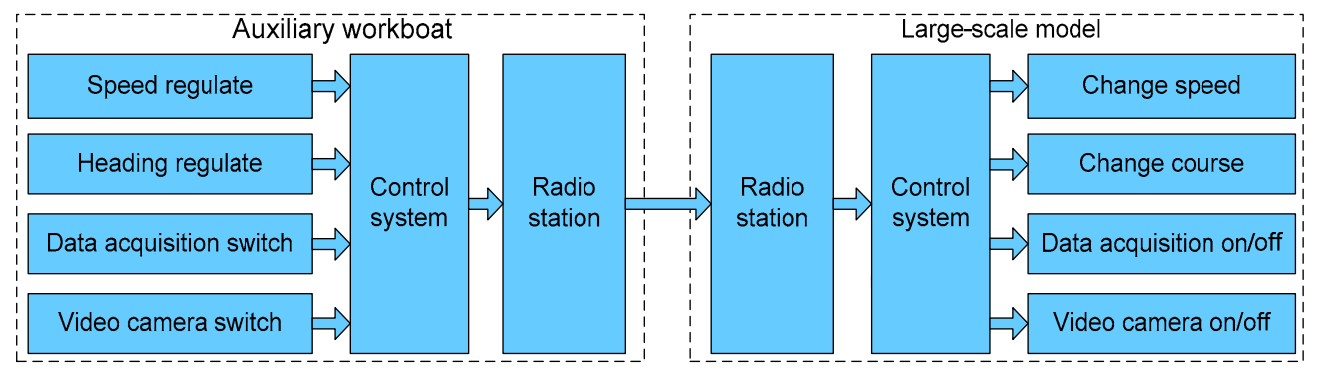

Fig. 5 Flowchart of the remote control system

A commercial autopilot system is installed onboard the model to control the rudders' angle. The GHP autopilot system consists of four main components: the course computer unit (CCU), the electronic control unit (ECU), the GHC user control interface, and the drive unit (Garmin, 2011). The CCU acts as the brain of the GHP and it contains the sensory equipment used to determine the heading. The ECU controls the drive unit based on information from the CCU. Engaging and steering the model can be achieved by a user control interface, which is onboard the auxiliary workboat. The drive unit adjusts the rudder by a set of double crank mechanisms to keep course. The drive unit has a hydraulic telescopic rod using planetary gears and a flat pancake electric motor with a capacity to generate $400 \mathrm{~kg}$ thrust or $100 \mathrm{~kg} \cdot \mathrm{m}$ torque at its maximum. The working principle diagram is shown in Fig. 6.

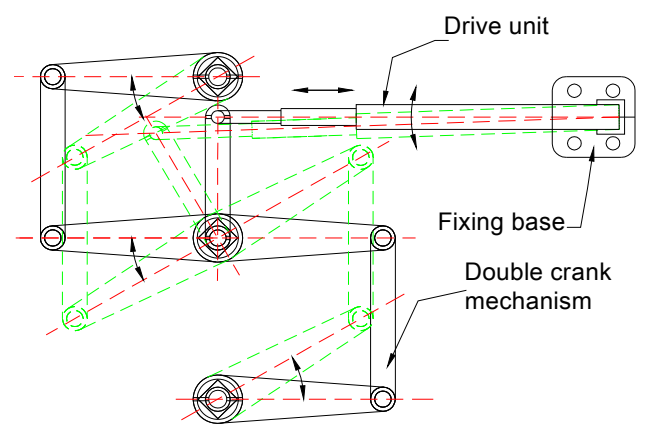

Fig. 6 Mechanism model of the drive unit

\subsubsection{Data acquisition system}

Two commercial 32-channel data collectors are used in the tests. A sectional VBM at the 2nd, 4th, 6th, 8th, 10th, and 12th stations, vertical accelerations at the 1 st section at the bow and the 19th section at the stern, and slamming pressures at the center line of the bow area are recorded by one of the data collectors.
The other data collector is used for measuring sea waves. The working duration of the battery is about $8 \mathrm{~h}$. The start and end of the data recording can be achieved by a signal transmitted by radio, as presented in Fig. 5. The sampling frequency of the data collectors is set at $100 \mathrm{~Hz}$ during the tests.

\subsubsection{Safeguard system}

Since the gaps between each pair of segments are connected by silicone gel, which is elastomeric and watertight but can easily be broken, a steady safeguard system for the model is of great importance. The safeguard system comprises seven hygrometer sensors, a control computer, and an alarm. The hygrometer sensors are fixed at the bottom of each segmented hull inside the model ship. A radio signal is emitted by whichever hygrometer sensor detects water. This signal is then transmitted to the control computer, and then the alarm on the deckhouse of the model will be raised for rescue.

\subsection{Experimental procedures}

The experimental activities were carried out in the sea area of Huludao Harbour $\left(40^{\circ} 43^{\prime} \mathrm{N}, 121^{\circ} 00^{\prime} \mathrm{E}\right)$ in China. It is an ideal location where various sea states appear frequently in an environmentally protected area. The sea states are different each day, so that all the test schemes can be completed within several days. Moreover, the sea state does not change rapidly, so that each test scheme is conducted under a steady sea state. The test area is sheltered so as to limit the effect of swell and to ensure that the waves that the model experiences are wind-generated waves. The sheltered area is large enough so that the large-scale model tests can be performed regardless of the model size and speed. Fig. 7 shows a Google map satellite view of the test field. 
In Fig. 7, there is a launching ramp of about $300 \mathrm{~m}$ long and with a slope of $3^{\circ}$. The launch of the model was achieved with the help of a crane. The experiment location is $5 \mathrm{~km}$ away from the coast. During the tests, the wind blew from deep-ocean to the beach. Tests were conducted at high tide to avoid the appearance of swell. This can be explained by the fact that the tidal waves spread from deep-ocean will be absorbed by the coastal beach during high tide. When the wave heights measured by the buoy met the needs of the tests, the model sailed following the routes intended. The auxiliary workboat kept a distance of $300 \mathrm{~m}$ from the ship model during the trial. The steersman steered and engaged the model by radio to make it sail as expected. Meanwhile, the buoy for the significant wave height meter was located at the center of the routes to ensure that the waves measured were consistent with the waves encountered by the model. Two video cameras were used to record the test procedures: one held by the crew on the auxiliary workboat to record the sailing state of the model, and the other fixed on deck of the model to record bow slamming and green water phenomena.

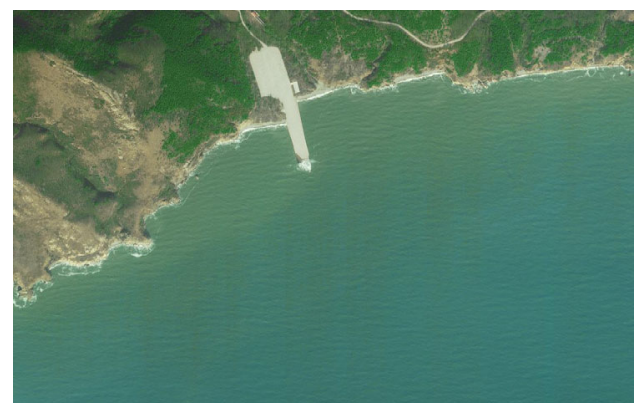

Fig. 7 Satellite view by Google map

\section{Measurement and analysis of sea waves}

A buoy wave meter, as shown in Fig. 8, is selected to measure the waves. An acceleration transducer fixed at the barycenter of the buoy is used to measure the vertical acceleration of waves. The data are recorded by the data collector onboard the wave measuring boat. The time interval for data recording was set at $0.02 \mathrm{~s}$ during the tests.

To obtain the frequency-domain spectra of measured waves, a spectral analysis method is adopted (Li, 2003; Sun et al., 2015). The autocorre- lation formula of the recorded vertical acceleration data is derived as

$$
R(\tau)=\lim _{T \rightarrow \infty} \frac{1}{T} \int_{0}^{T} \zeta^{\prime \prime}(t) \cdot \zeta^{\prime \prime}(t+\tau) \mathrm{d} t
$$

where $\tau$ is the preset sampling interval, $T$ is the time duration of the recorded wave acceleration data, and $\zeta^{\prime \prime}$ is the time history of vertical acceleration.

To obtain the spectrum of acceleration, the Fourier transform of Eq. (1) is carried out by

$$
S_{\zeta^{\prime \prime}}(\omega)=\frac{2}{\pi} \int_{0}^{\infty} R(\tau) \cos (\omega \tau) \mathrm{d} \tau
$$

where $\omega$ denotes the frequency.

To obtain the spectrum of wave surface elevation, the following equation is used:

$$
S_{\zeta}(\omega)=S_{\zeta^{\prime \prime}}(\omega) / \omega^{4}
$$

In addition, the significant wave height $H_{1 / 3}$ and period $T_{02}$ of the recorded waves can be obtained based on the wave spectral result:

$$
\begin{gathered}
H_{1 / 3}=4 \sqrt{m_{0}}, \\
T_{02}=2 \pi \sqrt{m_{0} / m_{2}},
\end{gathered}
$$

where $m_{n}$ is the $n$th moment of the estimated wave spectrum, $n=0,2$.

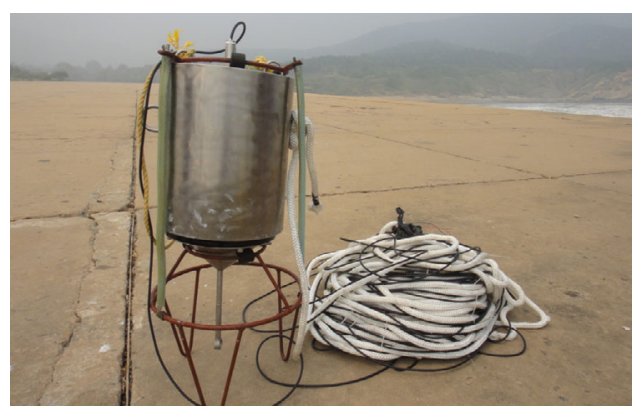

Fig. 8 Buoy wave meter

To confirm whether the coastal waves model suffered are applicable for this research, a comparison of the measured wave spectra with ISSC target 
spectra is carried out. ISSC spectrum was proposed and recommended at the 12th International Towing Tank Conference (ITTC) in 1969. Soon it became a widely used wave spectrum for naval architects. Furthermore, measurements of the waves at the test site were conducted in different seasons before implementation of the experiments, and the spectral results showed good agreement with ISSC spectra. The comparison of the spectra is conducted using a dimensionless form. In the spectral dimensionless analysis, the $x$ axis, i.e., wave frequency, is usually adopted as $\omega / \omega_{m}$, and the $y$ axis, i.e., spectral density, is usually adopted as $S(\omega) \omega_{m} / m_{0}$, where $\omega_{m}$ is the peak frequency (Yu, 1992).

Two typical sea states are considered: one corresponding to the extreme sea state and the other to the design sea state. The comparison of the wave spectra obtained and ISSC wave spectrum in dimensionless form is shown in Fig. 9. It can be confirmed that the measured spectra agree with the ISSC spectrum. The significant wave heights and periods calculated by Eqs. (4) and (5) for the two sea states are $0.584 \mathrm{~m}, 2.545 \mathrm{~s}$ and $0.392 \mathrm{~m}, 2.351 \mathrm{~s}$, for the extreme sea state and design sea state, respectively.

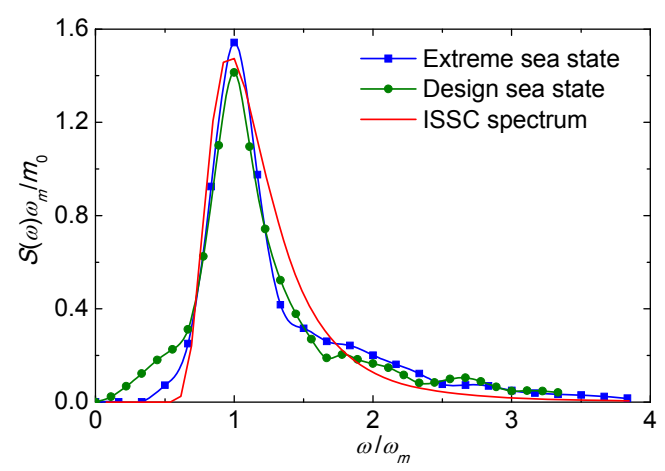

Fig. 9 Comparison of spectral results

The sea waves are short-crested waves and should be described by a 2D spectrum. However, the single point wave buoy can only give information for the overall spectrum considering the contribution of all directions at each frequency. A commonly used experiential directional spreading function is adopted in this study:

$$
D(\omega, \theta)=\left\{\begin{array}{c}
2 \cos ^{2} \theta / \pi, \quad-\frac{\pi}{2} \leq \theta \leq \frac{\pi}{2}, \\
0, \quad \text { elsewhere }
\end{array}\right.
$$

where $D(\omega, \theta)$ denotes the simplified directional spreading function, and $\theta$ denotes the angle between the component wave direction and the dominant wave direction.

The directional wave spectrum is assumed to be obtained by multiplying the 1D wave spectrum by the directional spreading function, which is expressed as

$$
S_{\zeta}(\omega, \theta)=S_{\zeta}(\omega) D(\omega, \theta)
$$

It is worth mentioning that the integral over 0 to $2 \pi$ of the directional spreading function at any frequency is unity:

$$
\int_{0}^{2 \pi} D(\omega, \theta) \mathrm{d} \theta=1
$$

The obtained directional wave spectra by combining the 1D spectra from the tests and the experiential directional spreading function for the extreme sea state and design sea state are shown in Figs. 10a and $10 \mathrm{~b}$, respectively.

(a)

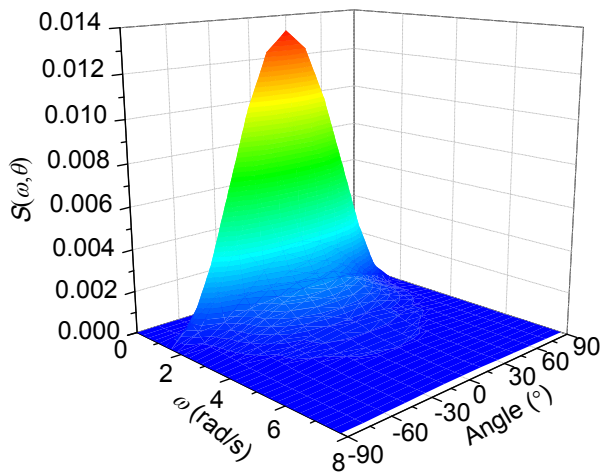

(b)

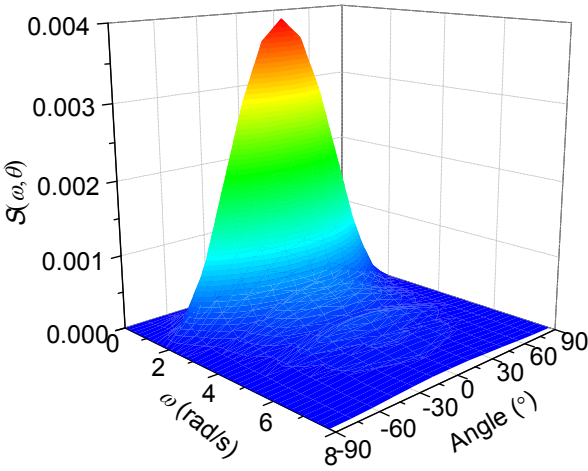

Fig. 10 Directional wave spectra

(a) Extreme sea state; (b) Design sea state 


\section{Test results of the large-scale model at sea}

As already mentioned, the large-scale model was tested at sea for hydroelasticity and seakeeping performance in correspondence to three different control variables, i.e., constant sea state, constant wave direction, and constant sailing speed. It is worth mentioning that this paper will focus on the test cases of the large-scale model in severe wave conditions in head seas. The responses of the ship model under the two aforementioned typical sea states are selected for further research. The first sea state is the extreme condition, which is the equivalent of significant wave height of $14.6 \mathrm{~m}$ for the real ship, and the test speed is $0.514 \mathrm{~m} / \mathrm{s}$, the equivalent of 5 knots of real ship speed. The second sea state is the design condition, which is the equivalent of significant wave height of $9.8 \mathrm{~m}$ for the real ship, and the test speed is $1.852 \mathrm{~m} / \mathrm{s}$, the equivalent of 18 knots of the real ship speed. Both of the two measurements were carried out in head wave conditions, i.e., the model sailed heading against the dominant wave direction during tests. Testing video camera screenshots are shown in Figs. 11 and 12. In Fig. 12 green water on deck and slamming phenomena occurred due to severe sea states with the sailing speed of 18 knots.

In Fig. 13, typical results of time history data for

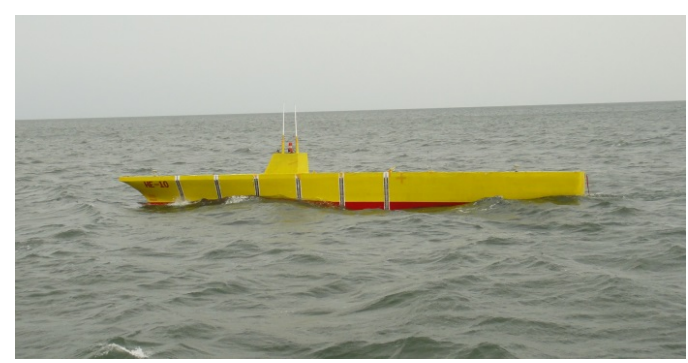

(a) seakeeping performance tests for corresponding sea states are reported. It includes test results for pitch, roll, and acceleration at the bow and stern areas. It can be seen clearly that, when the model is steered in a head sea, the roll motion is obvious with large amplitude, which is quite different from the result obtained in the laboratory measurement. In the laboratory test results the roll motion is nearly zero.

In Fig. 14, the time histories of VBM at different transverse sections of the model for corresponding sea states are reported. VBM time histories for the 2nd, 4th, 6th, 8th, 10th, and 12th sections are displayed in this order from top to bottom in these figures. The results are converted into the VBM of the real ship by using the similitude law. The measured VBM contains a small high-frequency component, which is caused by the transient vibration of the segmented model due to slamming (Kim et al., 2010; Lee et al., 2011). This is obvious at sections forward of the ship because of bow flare slamming in particular.

To investigate the distribution of loads along the ship, the spectral analysis method is adopted to calculate significant amplitude values of VBM at different stations. In addition, the extreme values that were experienced at different stations are also extracted from 200-s recorded data. The statistical

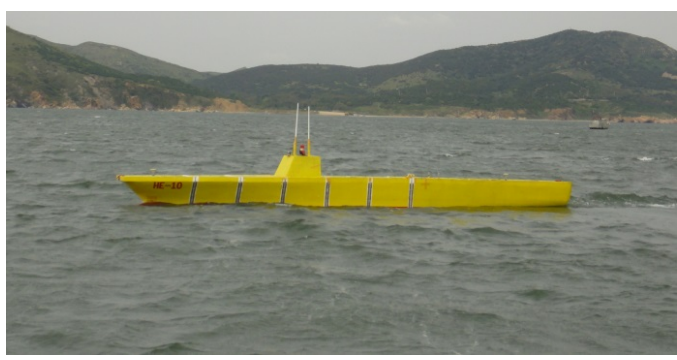

(b)

Fig. 11 Large-scale model recorded by crew during tests

(a) Extreme sea state; (b) Design sea state

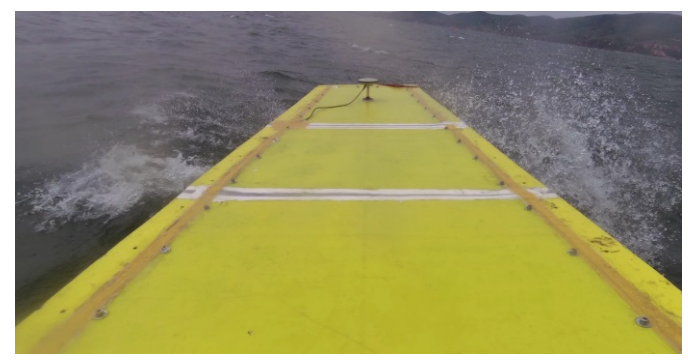

(a)

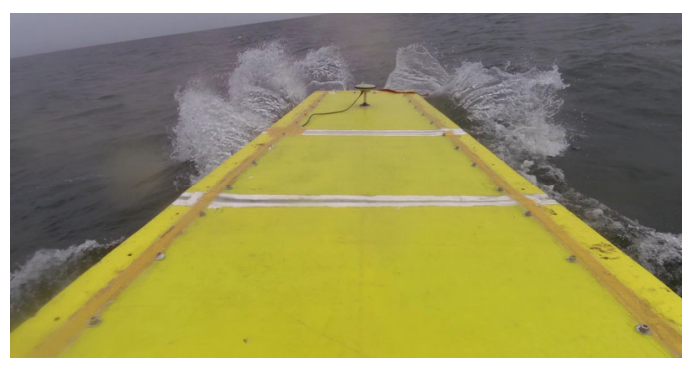

(b)

Fig. 12 Green water on deck and slamming phenomena recorded by video onboard the model (a) Green water on deck; (b) Slamming phenomena 


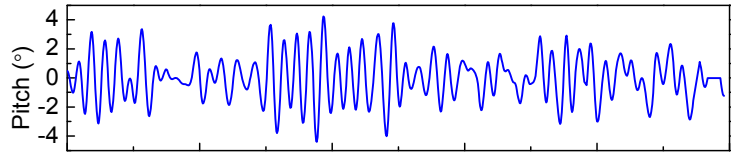

政:

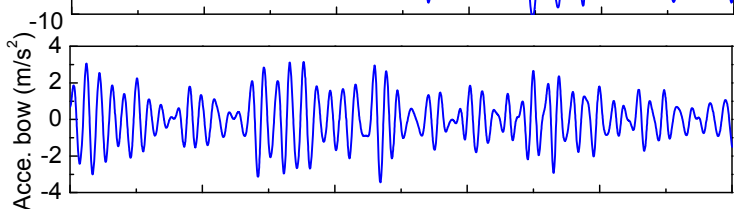

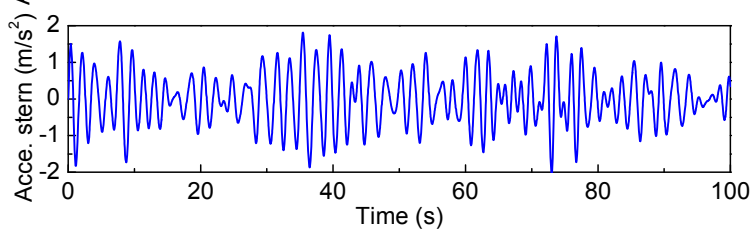

(a)

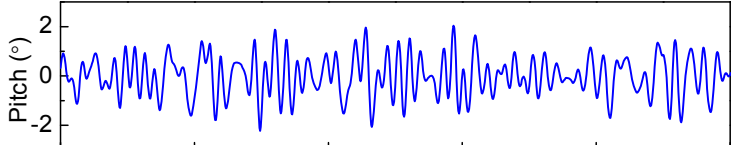

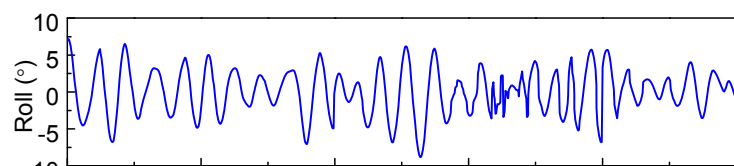

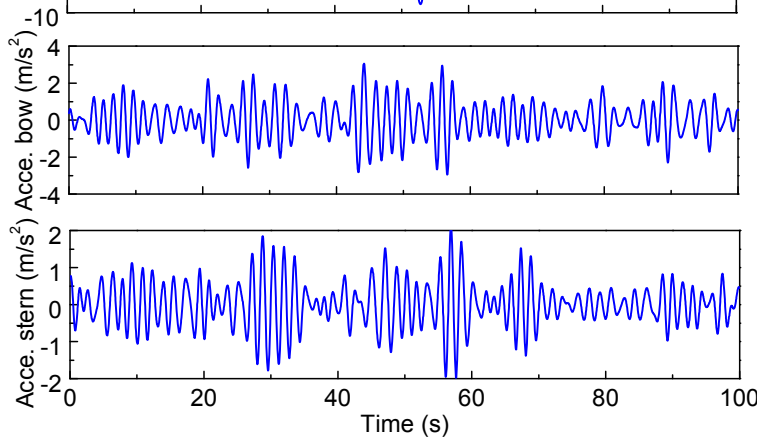

(b)

Fig. 13 Time histories of seakeeping performance data

(a) Extreme sea state; (b) Design sea state

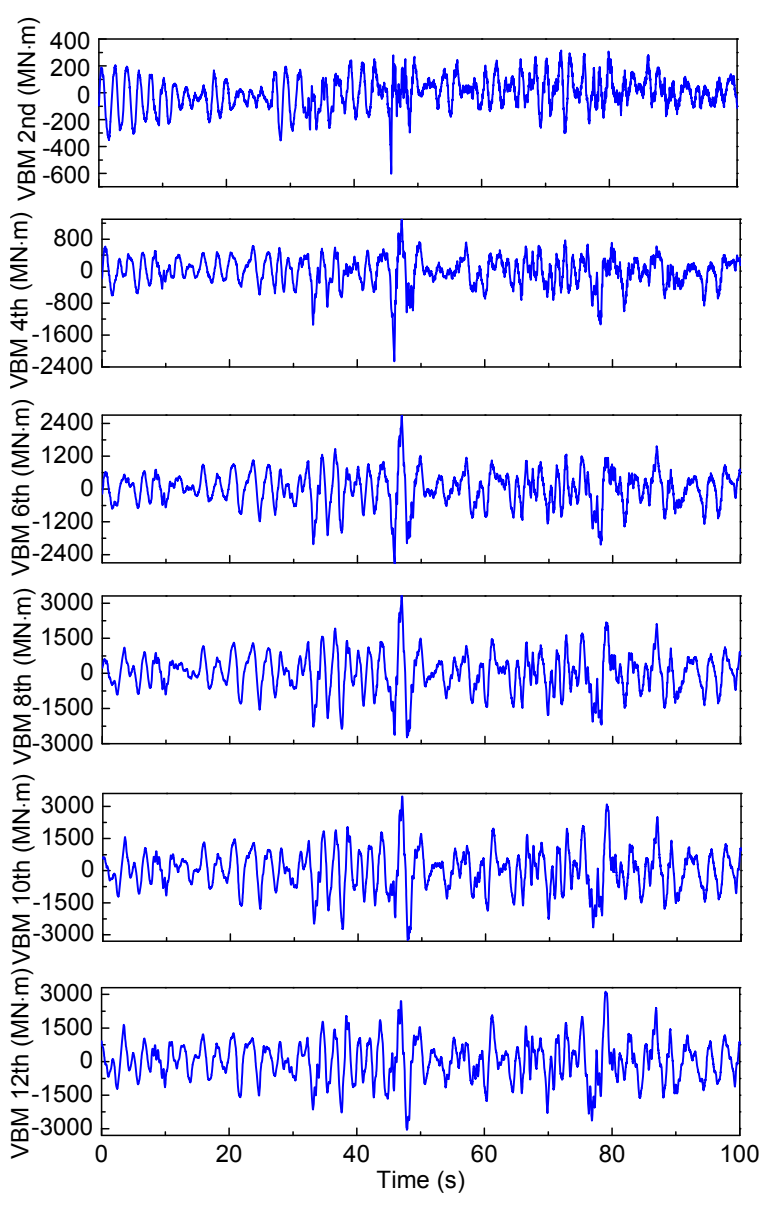

(a)

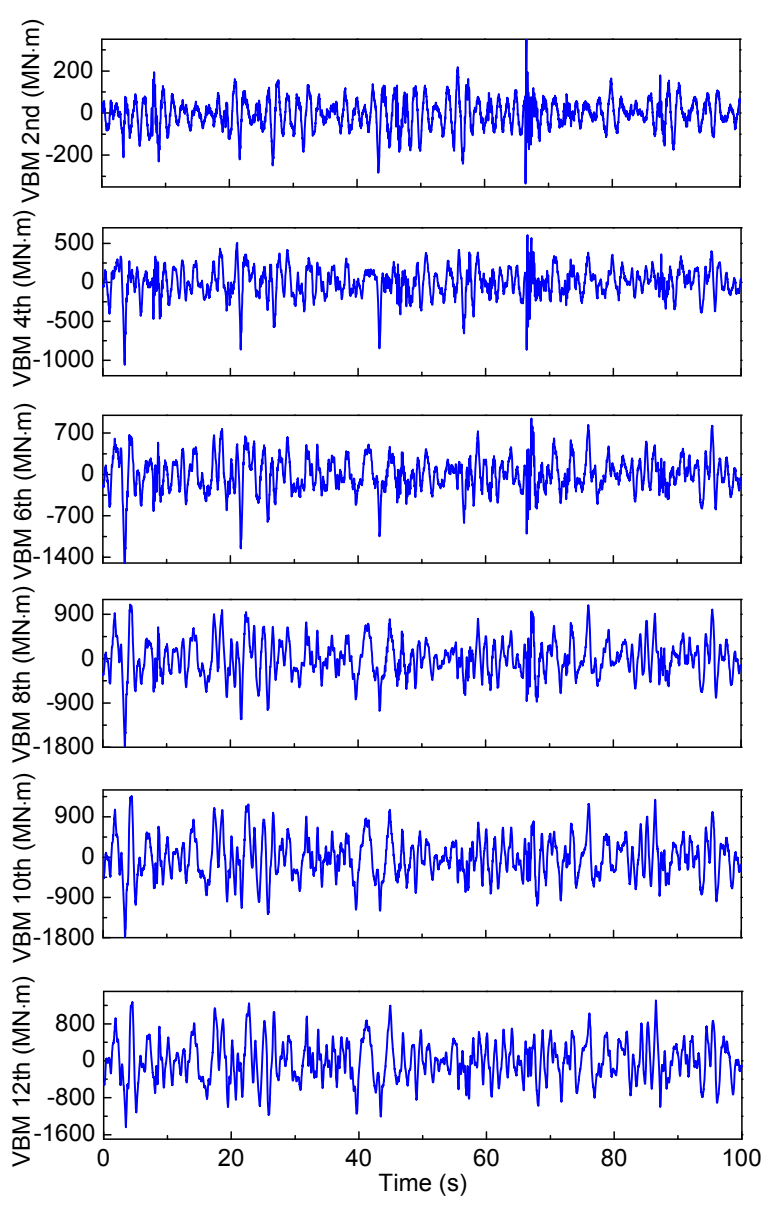

(b)

Fig. 14 VBM time histories at different sections

(a) Extreme sea state; (b) Design sea state 
results are shown in Table 2. In addition, the ratios of extreme value to significant amplitude value for each section along the ship are shown in Fig. 15.

Table 2 Statistical results of VBM

\begin{tabular}{crrrrr}
\hline & \multicolumn{4}{c}{ VBM $(\mathrm{MN} \cdot \mathrm{m})$} \\
\cline { 2 - 3 } Station & \multicolumn{2}{c}{ Extreme sea state } & & Design sea state \\
\cline { 2 - 3 } \cline { 5 - 6 } & Significant & Extreme & & Significant & Extreme \\
\hline 2 & 221.78 & 640.64 & & 164.38 & 437.84 \\
4 & 678.42 & 2222.04 & & 460.87 & 1293.34 \\
6 & 1146.51 & 3420.53 & & 725.31 & 1985.39 \\
8 & 1472.69 & 3398.00 & & 933.96 & 2232.18 \\
10 & 1750.15 & 3429.41 & & 1132.64 & 2184.41 \\
12 & 1609.11 & 3044.64 & & 1120.81 & 1966.82 \\
\hline
\end{tabular}

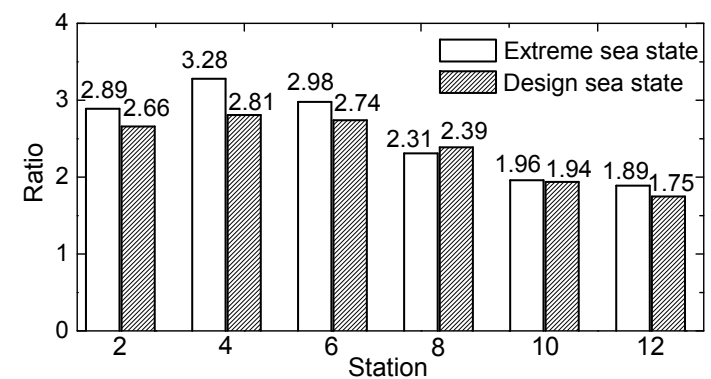

Fig. 15 Ratio of extreme value to significant value for each section along the ship

As seen from the results, the largest sectional VBM occurred at the 10th station, which is near the center of gravity of the model. The load significant values increase from the bow area to the amidships area with an almost linear relationship for both of the two conditions. The largest ratio of extreme value to significant value occurred at the 4th station. This can be attributed to the enormous slamming loads at the 4th station. The smallest ratio happened at the 12th station, which is the farthest station from the bow area. The ratios at stations 2,4 , and 6 under the extreme sea state are larger than the design sea state because of the flare slamming caused by severe seas. This indicates that enough attention should be paid to the local strength at the bow area of large ships with the flare bow during the ship design stage.

\section{Comparison of the small-scale model test in the tank}

After the large-scale model trial at sea, smallscale model experiments were conducted in the tank in order to study the differences caused by variations in the environment and scale effects. The small-scale ship model is made from FRP, the scale ratio of which is 1:50, with main dimensions reported in Table 1. The corresponding ship prototype of this small model is the same as the large-scale one. The layout of the sensors for wave loads and motions is the same as that in the large-scale model. The propulsion equipment is also installed on the small model to achieve sailing speeds by itself (Ren and Chen, 2012; Jiao et al., 2015). Photos of the two ship models are shown in Fig. 16.

(a)

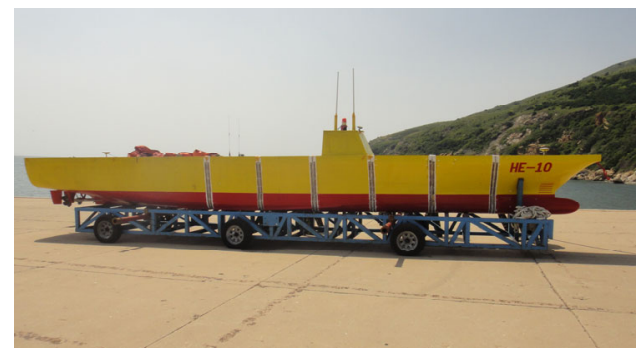

(b)

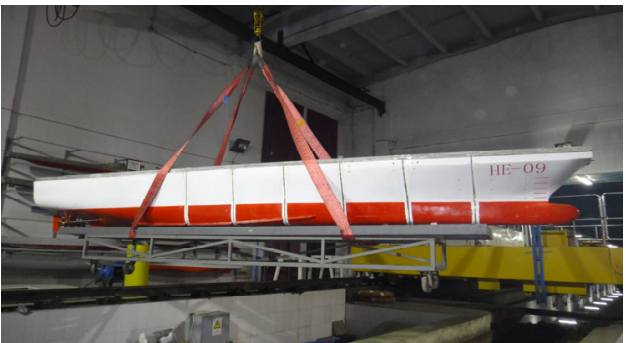

Fig. 16 Views of the two ship models

(a) Large-scale model ship; (b) Small-scale model ship

The small-scale model experiments were carried out in the tank at Harbin Engineering University (HEU), which has dimensions of $108 \mathrm{~m} \times 7 \mathrm{~m} \times 3.5 \mathrm{~m}$, for length, width, and depth, respectively. Waves are made by a rocker flap wave maker, and there is a damp plate on the opposite side of the wave maker. The model movements are measured by a seaworthiness instrument which has the capability of measurement with five degrees of freedom. Two poles of the seaworthiness instrument are fixed on the center line of the model for motion measurement.

The model tests were performed on long-crested irregular waves generated by ISSC target spectra. The environmental parameters such as significant wave heights, characteristic periods, and model speeds are consistent with the aforementioned sea trial data by use of the similitude law. Time histories of wave 
surface vertical movement are recorded by a capacitance wave meter near the wave generator. The comparisons of spectral analysis results of tank waves and sea waves in dimensionless form are presented in Fig. 17. The measured spectra in the tank agreed with the sea waves. The significant wave heights and periods of the two wave data points recorded are $0.304 \mathrm{~m}, 1.789 \mathrm{~s}$ and $0.187 \mathrm{~m}, 1.641 \mathrm{~s}$, for the extreme sea state and the design sea state, respectively.
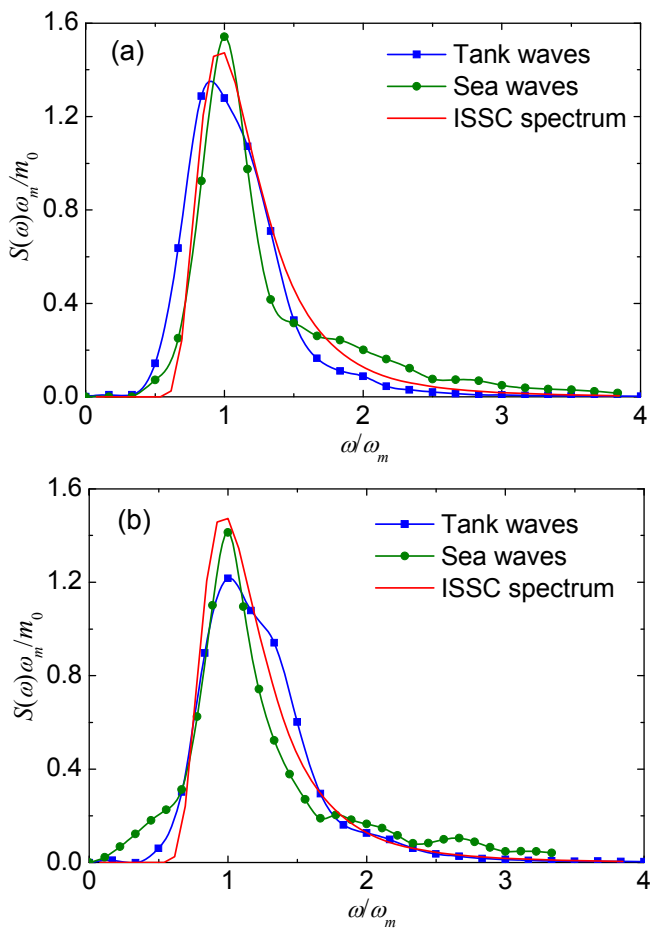

Fig. 17 Comparison of spectral analysis results of the tank and sea wave spectra

(a) Extreme sea state; (b) Design sea state

The waves generated by wave maker in tank are long-crested waves, which are different from the short-crested sea waves. To analyze the dominant waves from the overall sea waves, $\theta=0$ is substituted into Eqs. (6) and (7). The spectrum of dominant direction components is expressed as

$$
S(\omega, 0)=2 S_{\zeta}(\omega) / \pi
$$

The wave parameters corresponding to ship prototype for tank waves, sea waves, and dominant components of sea waves are listed in Table 3.

Photographs of the small-scale model tests in the tank are presented in Fig. 18. It is evident that the slamming or green water on deck seems to be more pronounced as compared with the tests results at sea. In Fig. 18b, because the deck is made of plexiglass and also due to the violent motions of model, the picture taken by the camera onboard the model is initially not clear. However, as a matter of fact, after careful observation it is clear that the bow has already pierced the water and a severe green water event has taken place.

Table 3 Comparison of wave parameters

\begin{tabular}{cccccc}
\hline \multirow{2}{*}{ Item } & \multicolumn{2}{c}{ Extreme sea state } & & \multicolumn{2}{c}{ Design sea state } \\
\cline { 2 - 3 } \cline { 5 - 6 } & $H_{1 / 3}(\mathrm{~m})$ & $T_{02}(\mathrm{~s})$ & & $H_{1 / 3}(\mathrm{~m})$ & $T_{02}(\mathrm{~s})$ \\
\hline Tank waves & 15.20 & 12.65 & & 9.35 & 11.60 \\
Sea waves & 14.60 & 12.73 & & 9.80 & 11.76 \\
$\begin{array}{c}\text { Sea waves } \\
\text { dominant }\end{array}$ & 11.65 & 12.73 & & 7.82 & 11.76 \\
\hline
\end{tabular}

(a)

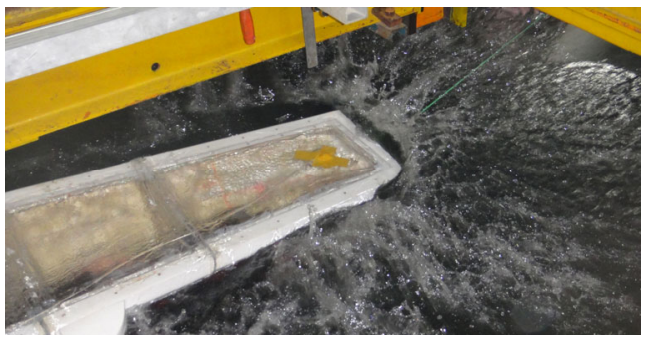

(b)

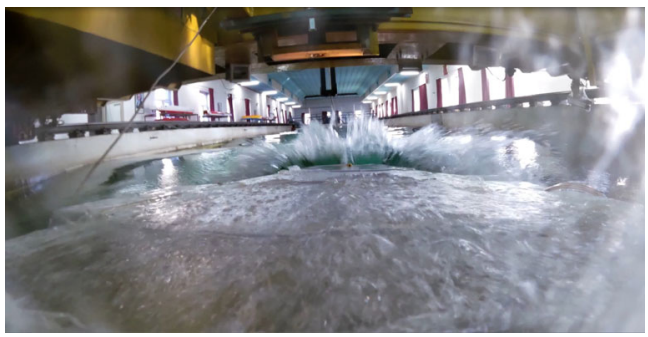

Fig. 18 Photos of small-scale model tests in the tank (a) Bow slamming phenomenon; (b) Green water on the deck

The test results of the small-scale model in the tank are analyzed and compared with those of the large-scale model. The statistics of the significant amplitude values of typical motion and load responses calculated by the spectral analysis method are presented in Table 4. In addition, the ratios of the small-scale model response amplitude values to the large-scale model amplitude values under equivalent sea states are calculated and shown in Fig. 19. The ratio of roll motion tends to decline with increasing sailing speed. However, ratios of other longitudinal motions tend to increase with increasing sailing speed. 
As seen from the results, longitudinal responses of the ship in the tank environment are more pronounced than at sea even at the equivalent sea state. This can be explained by the fact that the waves measured at sea are composed of component waves spreading from all directions. It is noteworthy that the responses induced by the component waves are very different from the responses induced by dominant waves. To investigate the response components caused by the dominant waves, responses under unit wave height are summarized in Table 5, where all of the three wave cases listed in Table 3 are considered. In addition, the ratios of response values of the small-scale model to the large-scale model for unit wave height are shown in Fig. 20. The responses under unit wave height caused by dominant waves are close to the tank test results, especially for the extreme sea state case. From the comparative analysis results, it can be concluded that the longitudinal responses of a ship sailing in head seas are mainly induced by

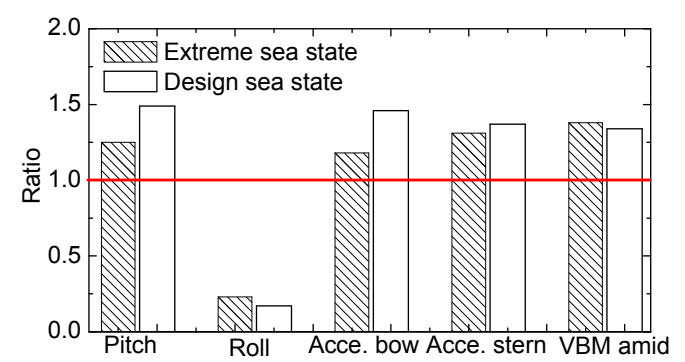

Fig. 19 Ratio of test results the oncoming waves. However, the roll motion of the ship is largely induced by component waves.

For completeness, the dimensionless response spectra of the large-scale and small-scale models are compared, as shown in Figs. 21-24. Curves of seakeeping performance response spectra in Figs. 21-23 are smooth after the smoothing process. However, as the VBM signals recorded during the experiments are neither linear nor stationary (Figs. 13 and 14), some high-frequency component loads caused by slamming events in the time histories are separated by fast Fourier transform (FFT). Time history of the total loads and the wave frequency component loads after Fourier filtering are presented in the inserts in Figs. $24 \mathrm{a}$ and $24 \mathrm{~b}$ for the extreme sea state and the design sea state, respectively.

The comparison of these two results shows that there exists a remarkable difference between the dimensionless spectral densities of the motion of the two models. It appears clearly that spectral densities

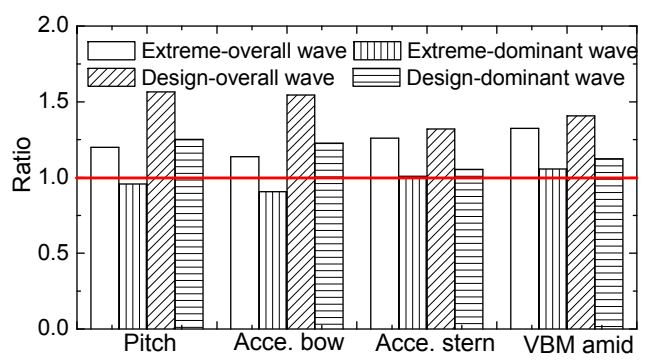

Fig. 20 Ratio of unit wave height responses

Table 4 Comparison of the significant amplitude values of responses

\begin{tabular}{ccccccc}
\hline Condition & Model & Pitch $\left(^{\circ}\right)$ & Roll $\left(^{\circ}\right)$ & $\begin{array}{c}\text { Acceleration at } \\
\text { bow }\left(\mathrm{m} / \mathrm{s}^{2}\right)\end{array}$ & $\begin{array}{c}\text { Acceleration at } \\
\text { stern }\left(\mathrm{m} / \mathrm{s}^{2}\right)\end{array}$ & $\begin{array}{c}\text { VBM at amidships } \\
(\mathrm{MN} \cdot \mathrm{m})\end{array}$ \\
\hline $\begin{array}{c}\text { Extreme sea state } \\
(V=5 \text { knots })\end{array}$ & Large-scale model & 3.01 & 5.08 & 2.12 & 1.40 & 1750.17 \\
\hline Sesign sea state & Large-scale model & 1.56 & 4.24 & 1.82 & 1.28 & 2414.51 \\
$(V=18$ knots $)$ & Small-scale model & 2.33 & 0.72 & 2.67 & 1.62 & 1132.64 \\
\hline
\end{tabular}

Table 5 Comparison of the responses under unit wave height

\begin{tabular}{clccccc}
\hline Condition & \multicolumn{1}{c}{ Waves } & Pitch $\left(^{\circ}\right)$ & \multirow{2}{*}{ Roll $\left(^{\circ}\right)$} & $\begin{array}{c}\text { Acceleration at } \\
\text { bow }\left(\mathrm{m} / \mathrm{s}^{2}\right)\end{array}$ & $\begin{array}{c}\text { Acceleration at } \\
\text { stern }\left(\mathrm{m} / \mathrm{s}^{2}\right)\end{array}$ & $\begin{array}{c}\text { VBM at amidships } \\
(\mathrm{MN} \cdot \mathrm{m})\end{array}$ \\
\hline \multirow{2}{*}{$\begin{array}{c}\text { Extreme sea state } \\
(V=5 \text { knots })\end{array}$} & Sea waves & 0.206 & 0.348 & 0.145 & 0.096 & 119.875 \\
& Sea waves dominant & 0.258 & - & 0.182 & 0.120 & 150.229 \\
& Tank waves & 0.247 & 0.077 & 0.165 & 0.121 & 158.849 \\
\hline \multirow{2}{*}{$\begin{array}{c}\text { Design sea state } \\
(V=18 \text { knots })\end{array}$} & Sea waves & 0.159 & 0.433 & 0.185 & 0.131 & 115.576 \\
& Sea waves dominant & 0.199 & - & 0.233 & 0.164 & 144.839 \\
& Tank waves & 0.249 & 0.077 & 0.286 & 0.173 & 162.764 \\
\hline
\end{tabular}



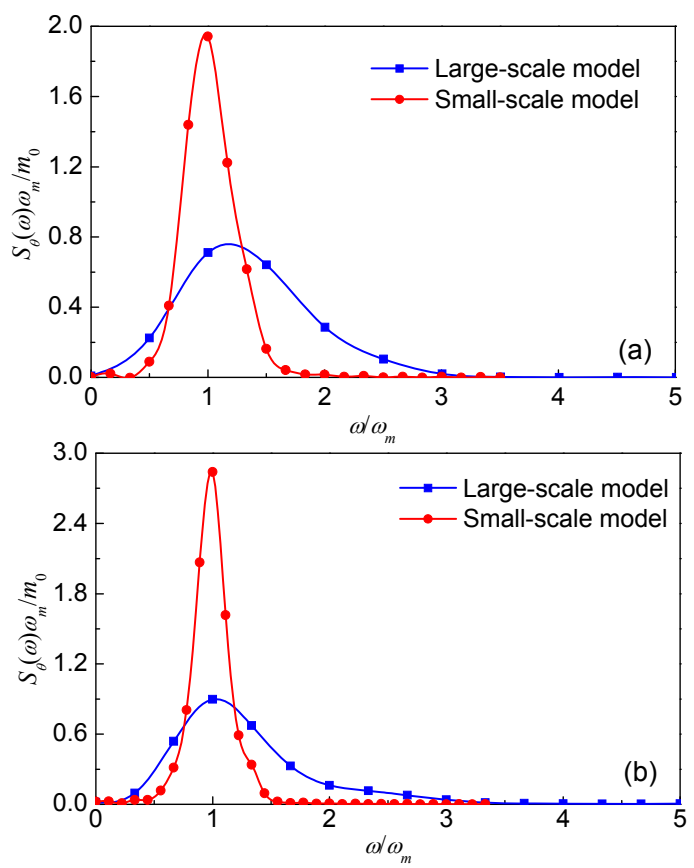

Fig. 21 Comparison of dimensionless pitch spectra: (a) extreme sea state; (b) design sea state
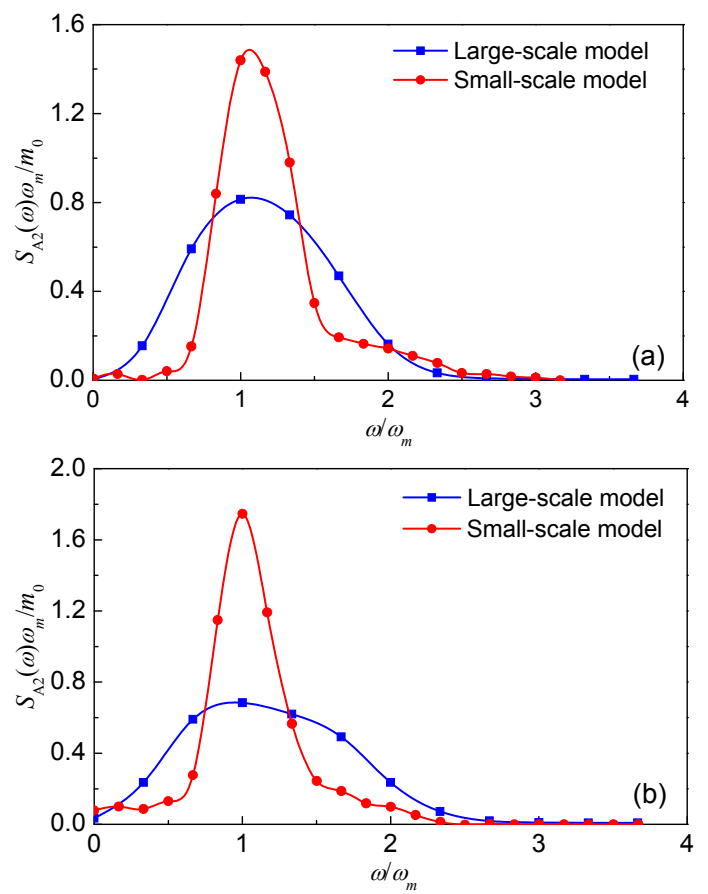

Fig. 23 Comparison of dimensionless stern acceleration spectra: (a) extreme sea state; (b) design sea state

of the small-scale model test in the tank center around the peak frequency with a narrow-banded distribution form. However, spectral densities of the large-scale model test at sea disperse over a broad-banded range.
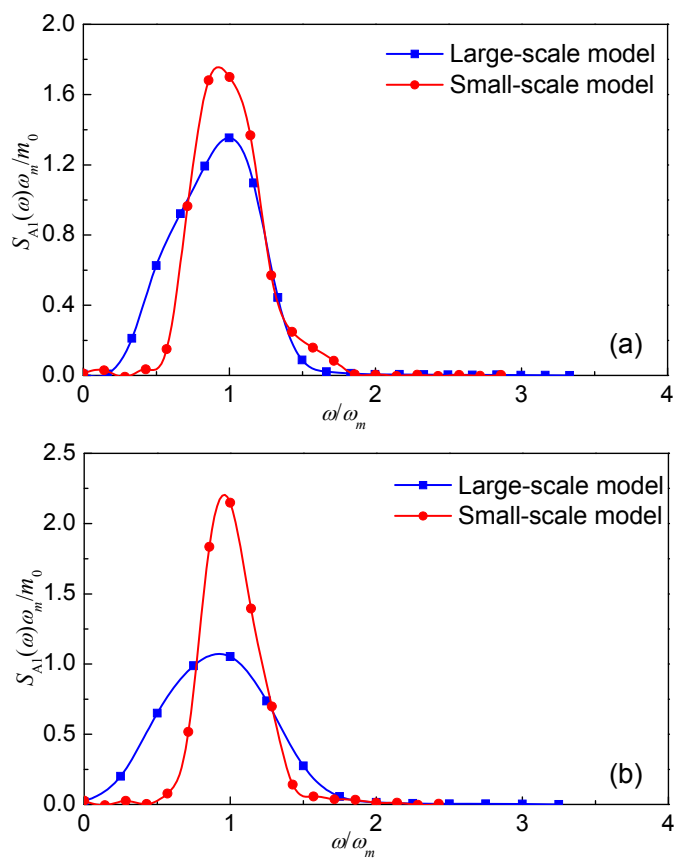

Fig. 22 Comparison of dimensionless bow acceleration spectra: (a) extreme sea state; (b) design sea state
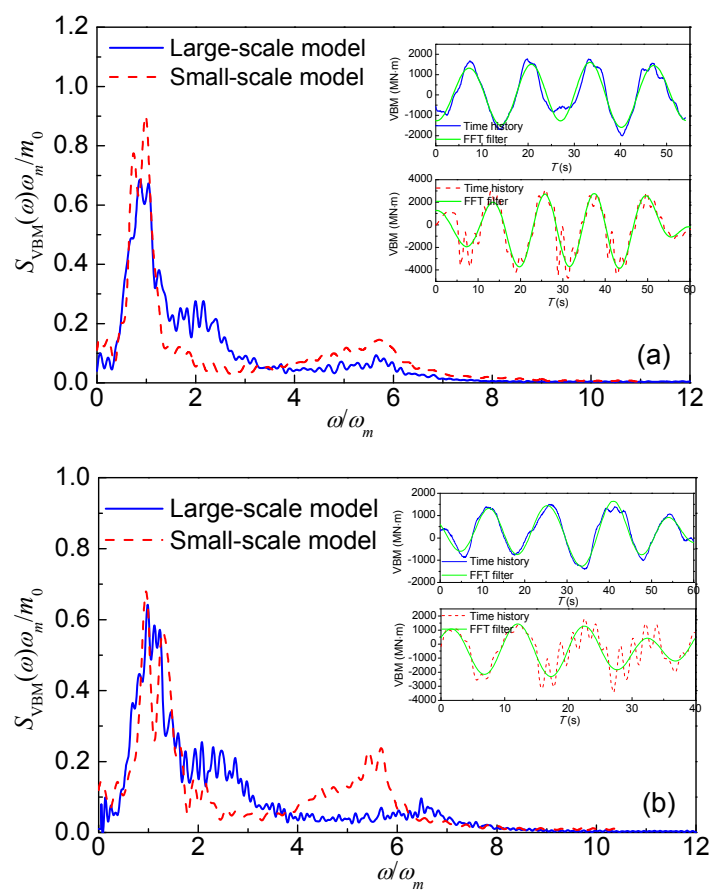

Fig. 24 Comparison of dimensionless VBM spectra: (a) extreme sea state; (b) design sea state

The results of VBM spectra show that there exists more high-frequency components around $\omega=6 \omega_{m}$ in small-scale model tests than those in large-scale model tests. The reason is that slamming phenomenon 
occurred more frequently and was more pronounced in the tank model tests than in sea trials under the equivalent sea state.

From the comparison, it can be concluded that the coupled motions of six degrees of freedom for the large-scale model under 3D wind-generated waves are obvious; the model is similar to a real vessel sailing situation. Roll and yaw motions, which disperse the energy of a longitudinal response of the ship, tend to be under-estimated by the traditional study of small-scale model tests carried out in towing tanks. In the case of the tank experiment of the small-scale model, the total energy can be dispersed by only longitudinal motions. However, in the case of the large-scale model tests at sea, the total energy can be dispersed by longitudinal motions and also by roll and yaw motions.

\section{Numerical approach}

\subsection{Comparison of the results}

In-house-developed software named the Wave Loads Calculation System (WALCS) is adopted to calculate the responses of the ship under 3D sea waves. The software is based on 3D frequencydomain potential theory. More information about the program can be found in (Zhang et al., 2001; Li, 2009). The hydrodynamic mesh model of the ship prototype is shown in Fig. 25.

(a)
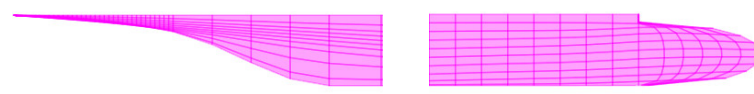

(b)

Fig. 25 Hydrodynamic mesh model

(a) Hull grids; (b) Underwater grids at stern and bow areas

The software is used to calculate the response amplitude operators (RAOs) corresponding to sailing speeds of 5 knots and 18 knots of different sailing heading angles. The results of the RAOs are shown in Fig. 26.
By substituting the 2D wave spectra in Fig. 10 and the RAOs in Fig. 26 into the following formula, $2 \mathrm{D}$ response spectra of the ship are obtained:

$$
\begin{aligned}
& S\left(\omega, H_{1 / 3}, T, V, \beta+\theta\right) \\
& \quad=H^{2}(\omega, V, \beta+\theta) S_{\zeta}\left(\omega, H_{1 / 3}, T, \theta\right) .
\end{aligned}
$$

In the simulations, $\beta=0$ is adopted, which corresponds to the head wave condition. The 0 th moment of the response spectrum can be obtained by

$$
\begin{aligned}
m_{0}( & \left.H_{1 / 3}, T, V, \beta\right) \\
\quad & \int_{-\pi / 2}^{\pi / 2} \int_{0}^{\infty} S\left(\omega, H_{1 / 3}, T, V, \beta+\theta\right) \mathrm{d} \omega \mathrm{d} \theta .
\end{aligned}
$$

Then the significant amplitude values of motion and load can be obtained by Eq. (4). The results of the computation and test significant amplitude values, as well as the difference between the two results are summarized in Table 6 . The calculated results of pitch and accelerations show good agreement with the tested results. However, the calculated values of roll and VBM are about $13 \%-18 \%$ larger than the test values. It is worth mentioning that results considering directional wave spreading from the numerical approach are closer to the large-scale model tests when compared with the small-scale model test results in long-crested waves.

\subsection{Influence of spreading functions}

To investigate the influence of the spreading functions on the ship response results, different spreading functions are adopted by the software, and the results are compared. The general inductive formula of spreading functions is expressed as follows:

$$
D(\omega, \theta)=\frac{\Gamma(n / 2+1)}{\sqrt{\pi} \Gamma(n / 2+1 / 2)} \cos ^{n} \theta, \quad-\frac{\pi}{2} \leq \theta \leq \frac{\pi}{2},
$$

where $\Gamma(\cdot)$ is the gamma function.

In this study, cases of $n$ ranging from 1 to 8 are considered. The direction spreading functions corresponding to cases of $n=1-8$ are shown in Fig. 27. The interface of the software spreading function option is shown in Fig. 28. 


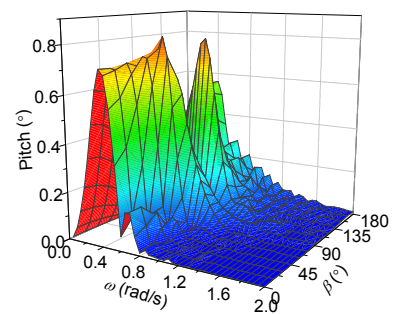

(a)

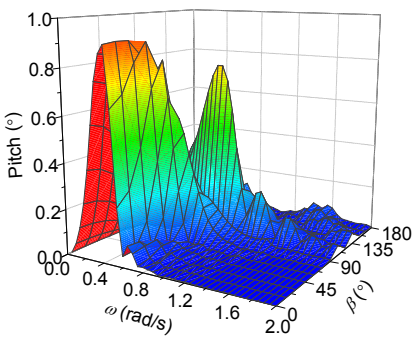

(e)

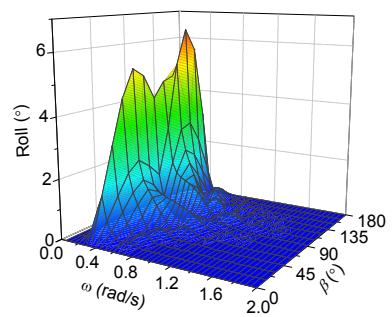

(b)

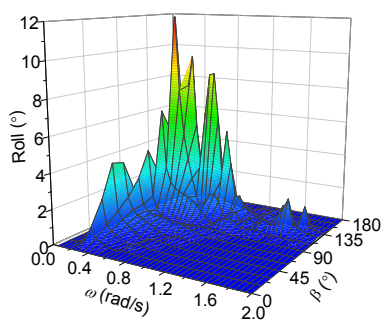

(f)

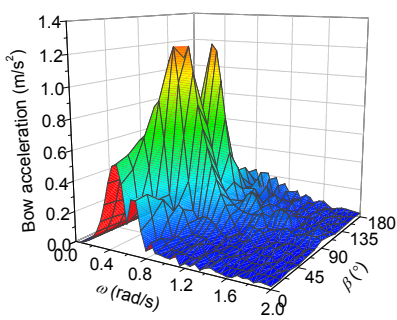

(c)

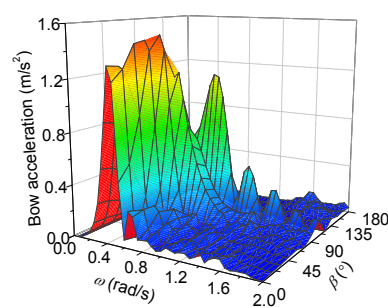

(g)

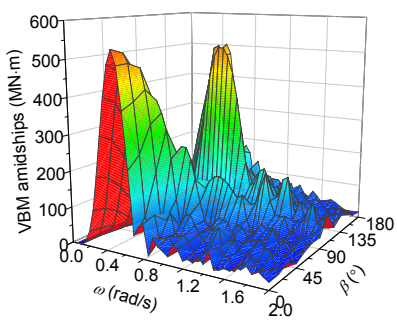

(d)

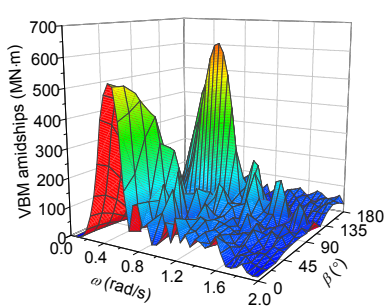

(h)

Fig. 26 Response amplitude operators

(a) Pitch, 5 knots; (b) Roll, 5 knots; (c) Bow acceleration, 5 knots; (d) VBM amidships, 5 knots; (e) Pitch, 18 knots; (f) Roll, 18 knots; (g) Bow acceleration, 18 knots; (h) VBM amidships, 18 knots

Table 6 Comparison of calculated and tested results of ship response

\begin{tabular}{clccccc}
\hline Condition & Approach & Pitch $\left(^{\circ}\right)$ & Roll $\left(^{\circ}\right)$ & $\begin{array}{c}\text { Acceleration at } \\
\text { bow }\left(\mathrm{m} / \mathrm{s}^{2}\right)\end{array}$ & $\begin{array}{c}\text { Acceleration at stern } \\
\left(\mathrm{m} / \mathrm{s}^{2}\right)\end{array}$ & $\begin{array}{c}\text { VBM at amidships } \\
(\mathrm{MN} \cdot \mathrm{m})\end{array}$ \\
\hline \multirow{2}{*}{$\begin{array}{c}\text { Extreme sea state } \\
(V=5 \text { knots })\end{array}$} & Calculation & 3.21 & 5.96 & 2.02 & 1.36 & 1982.08 \\
& Experiment & 3.01 & 5.08 & 2.12 & 1.40 & 1750.17 \\
\cline { 2 - 7 } & Difference & $6.64 \%$ & $17.32 \%$ & $-4.72 \%$ & $-2.86 \%$ & $13.25 \%$ \\
\hline \multirow{2}{*}{$\begin{array}{c}\text { Design sea state } \\
(V=18 \text { knots })\end{array}$} & Calculation & 1.74 & 4.90 & 1.97 & 1.41 & 1293.11 \\
\cline { 2 - 7 } & Experiment & 1.56 & 4.24 & 1.82 & 1.28 & 1132.64 \\
\hline
\end{tabular}

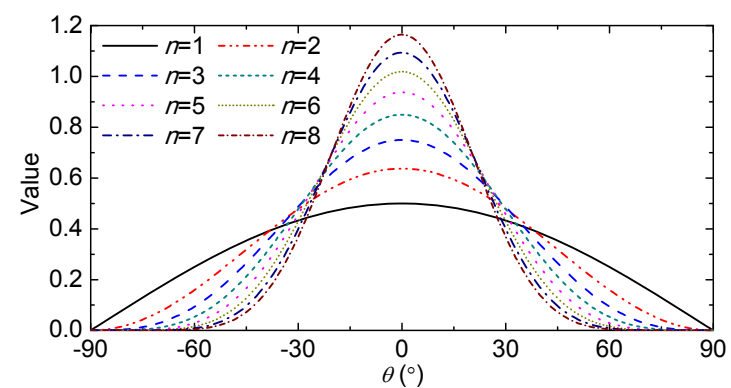

Fig. 27 Comparison of spreading functions with different $n$

The response significant values corresponding to the spreading function case of $n=2$ are regarded as the reference and the response results corresponding to the cases of $n=1-8$ are compared with the case of $n=2$. The ratios of the cases of $n=1-8$ to the case of $n=2$ are shown in Fig. 29.

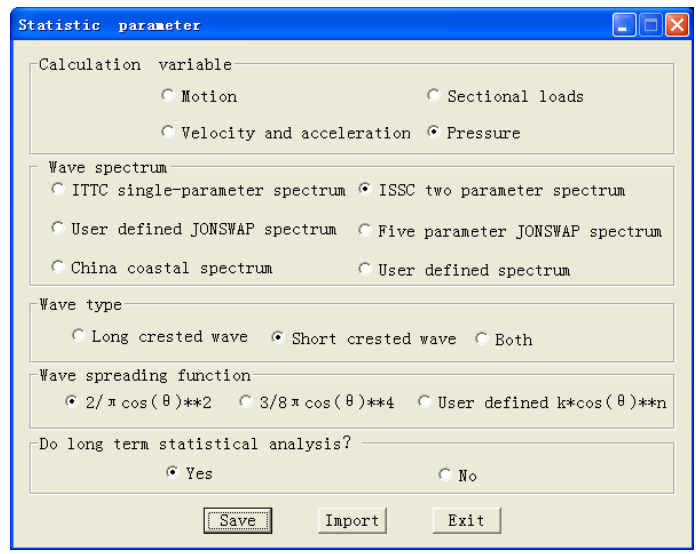

Fig. 28 Interface of the spreading function option

As seen from the results, the spreading functions have more influence on roll motion than longitudinal 
responses. When $n$ increases, roll motion decreases rapidly. When $n$ tends to infinity, i.e., the incident waves are long-crested, roll motion will be zero. The VBMs corresponding to the case of $n=8$ are about $11.1 \%$ larger than that of $n=2$ for both of the two conditions. However, spreading functions have minimum influence on pitch and accelerations; the difference is less than $6 \%$ for the cases of $n=2-8$.
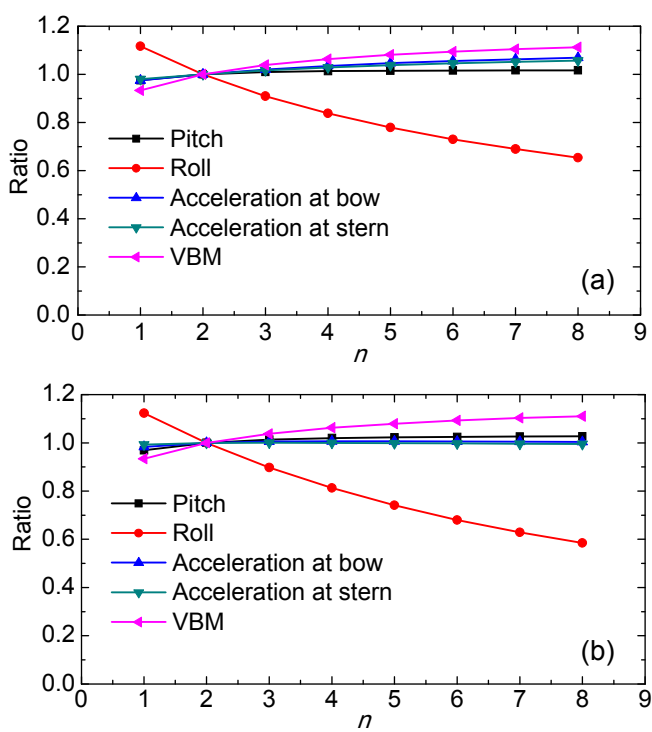

Fig. 29 Influence of spreading on the results

(a) Extreme sea state; (b) Design sea state

It can be concluded that the differences between test and calculated results in Table 6 are partly caused by the selection of spreading function. Since the experiential directional spreading function corresponding to the case of $n=2$ used in the study is a conservative choice, the test results are smaller than the tank model results.

\section{Conclusions}

The proposed technical details of the large-scale model tests at sea are feasible, as shown by the tests carried out at Huludao Harbor and the data obtained. Therefore, the proposed testing system is reliable and capable. The large-scale model tests clearly demonstrate the advantages of testing large models at sea. The tests are conducted in short-crested, directional, wind-generated sea waves. The models are tested with their superstructure and bilge keel so that the wind as well as current effects can be taken into consideration. By all accounts, this environment is definitely more realistic than the tank environment. From the tests of the models and the numerical results, the following conclusions are obtained:

1. By comparing and analyzing the results of the large-scale model test at sea and the small-scale model test in the tank, we find that there exist distinct differences in the model responses even at the equivalent sea state. Longitudinal responses of the ship in the tank environment are more pronounced than when at sea. The longitudinal responses of a ship sailing in head seas are mainly induced by the oncoming waves. However, the roll motion of the ship is largely induced by component waves.

2. In this study, it was shown that six degrees of freedom coupled motions of the large-scale model test are similar to actual conditions of real vessels. The traditional model test under long-crested waves in the towing tank over-estimates the motion and wave load response. However, the results of motions and wave loads from large-scale model tests carried out at sea are more reasonable for ship design and research.

3. Compared with the large-scale model experimental results, the linear calculation code WALCS over-estimates $13 \%-18 \%$ of the roll and VBM responses of the ship for the directional spreading function case of $n=2$. The pitch and acceleration results show good agreement between test and calculated results.

4. According to the numerical approach, the spreading functions have considerable influence on roll motion, moderate influence on VBM, and minimum influence on pitch and acceleration.

In this study, a single point wave buoy, which can record only the overall waves from all the spreading directions, is used to measure sea waves. As a supplement to this, the presumptive directional function is used to calculate the wave directional spectra. In future research, a wave meter for directional spectrum measurement will be developed.

\section{References}

Chen, Z.Y., Ren, H.L., Li, H., et al., 2012. The wave load experimental investigation of a segmented model of a very large ship based on variable cross-section beams. Journal of Harbin Engineering University, 33(3): 263-268 (in Chinese).

http://dx.doi.org/10.3969/j.issn.1006-7043.201103042 
Coraddu, A., Dubbioso, G., Mauro, S., et al., 2013. Analysis of twin screw ships' asymmetric propeller behaviour by means of free running model tests. Ocean Engineering, 68:47-64.

http://dx.doi.org/10.1016/j.oceaneng.2013.04.013

Garmin, 2011. GHPTM 12 Installation Instructions. Garmin International Inc.

Grigoropoulos, G.J., Katsaounis, G.M., 2004. Measuring procedures for seakeeping tests of large-scaled ship models at sea. 13th IMEKO TC4 Symposium on Measurements for Research and Industrial Applications, IMEKO-International Measurement Federation Secretariat, Athens, Greece, p.135-139.

Jiao, J.L., Ren, H.L., Adenya, C.A., 2015. Experimental and numerical analysis of hull girder vibrations and bow impact of a large ship sailing in waves. Shock and Vibration, 2015:706613.

http://dx.doi.org/10.1155/2015/706163

Kim, S., Yu, H.C., Hong, S.Y., 2010. Segmented model testing and numerical analysis of wave-induced extreme and springing loads on large container carriers. Proceedings of the 20th International Offshore and Polar Engineering Conference (ISOPE), Beijing, China, p.385-392.

Lee, Y., White, N., Wang, Z.H., et al., 2011. Comparison of springing and whipping responses of model tests with predicted nonlinear hydroelastic analyses. Proceedings of the 21st International Offshore and Polar Engineering Conference (ISOPE), Maui, Hawaii, USA, p.453-460.

Li, H., 2009. 3-D Hydroelasticity Analysis Method for Wave Loads of Ships. PhD Thesis, Harbin Engineering University, Harbin, China (in Chinese).

Li, J.D., 2003. Seakeeping Performance of Ships. Harbin Engineering University Press, Harbin, China, p.27-28 (in Chinese).

Ren, H.L., Chen, Z.Y., 2012. Effect of self propulsion and towing test on ship load response. Journal of Huazhong University of Science and Technology, 40(11):84-88 (in Chinese). http://dx.doi.org/10.13245/j.hust.2012.11.021

Shi, S.J., 2007. Research on the Experimental Technique of the Physical Simulation Testing of the Large Scale Model in Real Waves. MS Thesis, Harbin Engineering University, Harbin, China (in Chinese).

Sun, S.Z., Li, J.D., Zhao, X.D., 2009. Experimental research on large scale model test in real ocean wave environment. Journal of Harbin Engineering University, 5(30): 475-480 (in Chinese). http://dx.doi.org/10.3969/j.issn.1006-7043.2009.05.001

Sun, S.Z., Li, J.D., Zhao, X.D., et al., 2010. Remote control and telemetry system for large-scale model test at sea. Journal of Marine Science and Application, 9(3): 280-285. http://dx.doi.org/10.1007/s11804-010-1008-3

Sun, S.Z., Ren, H.L., Zhao, X.D., et al., 2015. Experimental study of two large-scale models' seakeeping performance in coastal waves. Brodogradnja, 2(66):47-60.
Wang, C.T., 2009. Research on the Experimental System for the Physical Simulation Testing of the Large Scale Model at Sea. MS Thesis, Harbin Engineering University, Harbin, China (in Chinese).

Yu, Y.X., 1992. Random Wave and Its Applications to Engineering. Dalian University of Technology Press, Dalian, China, p.162-165 (in Chinese).

Zhang, H.B., Ren, H.L., Song, J.Z., et al., 2001. Method of 3D grid auto-generation of ship wet surface. Shipbuilding of China, 4(42):61-65 (in Chinese).

Zhao, F., 2008. Research on the Experimental Technique of the Movement Performance Physical Simulation Testing of the Large Scale Model in Real Waves. MS Thesis, Harbin Engineering University, Harbin, China (in Chinese)

\section{中文概要}

\section{题 目: 实际海浪环境中大尺度自航船模的水弹性与耐波 性试验研究}

目 的：为研究船舶在实际海浪环境中的水弹性与耐波 性, 本文提出一种新型模型试验技术。将相同 船型不同尺度的模型分别在近海环境和水池环 境中测量的试验数据进行比较, 分析两种试验方 法所得结果的差异, 以说明水池模型试验方法所 存在的问题, 从而进一步证明新型试验技术的优 越性。

创新点：1. 提出大尺度自航模型在实际海浪环境中实施水 动力试验的技术和方法; 2 . 将大尺度模型试验结 果与传统水池模型试验结果进行比较, 分析二者 的差异。

方 法: 针对某母型船, 分别建造缩尺比为 1:25 和 1:50 的大尺度模型和小尺度模型。大尺度模型在自然 海域的三维海浪中进行试验测量, 而小尺度模型 在水池长峰不规则波中进行试验测量。测量过程 中保证两者的控制参数相似, 并分析试验结果存 在的差异。将数值计算的结果与大尺度模型试验 的结果进行比较, 并基于数值计算分析海浪的方 向分布函数对结果的影响。

结 论: 在近海海域中开展的大尺度模型耐波性与波浪载 荷试验表明, 本文提出的试验测试系统和试验方 案是可行的。大尺度模型试验是在自然海浪环境 中进行的, 比水池环境更接近实船的实际航行环 境, 所得数据对于船舶设计和研发具有更高的参 考价值和意义。

关键词: 水弹性; 耐波性; 分段模型试验; 大尺度模型试 验; 海试; 尺度效应 